\title{
Evaluation of the Role of the Silymarin in Modulating the Cytotoxicity of Sofosbuvir and Ribavirin as Antiviral Drugs in Mice Bone Marrow and Sperm
}

M.E.Zowail, N.A.El kamshishy and E.H.Khater

Zoology Dept., Faculty of Science, Benha Univ., Benha, Egypt

E-Mail: noha.elkamshishy@yahoo.com

\begin{abstract}
Sofosbuvir (S) (sovaldi) is a nucleotide analog, which is a highly active NS5B polymerase inhibitor in HCV. Sovaldi has shown high efficacy against HCV in combination with and without PEG-INF, among other medications. Ribavirin $(\mathrm{R})$ is an antiviral drug which is non-selective, antihepatitis. Ribavirin has only been used in combination for treating chronic HCV infection. Silymarin (SL) is a natural antioxidant derived from the seeds and fruits of the Silybum marianum plant(Milk thistle). It's known for its impact on hepatoprotection. The goal of this study is to determine the protective effect of silymarin on the chromosome and sperm as a natural product against the side effects of sofosbuvir and ribavirin as an antiviral drug. Intraperitoneally (i.p.), male albino mice (weight 25-30 g) were injected with Sofosbuvir at a dose level of $50 \mathrm{mg} / \mathrm{kg} /$ day, ribavirin at a dose level of 20, $\mathrm{mg} / \mathrm{kg} / \mathrm{day}$, and Silymarin at a dose level of $70 \mathrm{mg} / \mathrm{kg} /$ day injections for five consecutive days, by various means. Mice were slaughtered 24 hours later. Chromosomal abnormalities and morphology of the sperm head were studied using classical cytogenetic methods. Tests showed that Sofosbuvir and Ribavirin caused abnormalities in the structural chromosomal aberration and sperm head. Although silymarin induces reduction in all injected forms of these abnormalities.
\end{abstract}

Keywords: Sofosbuvir, Ribavirin, Silymarin, Chromosomal aberrations, Sperm abnormalities.

\section{Introduction}

Sofosbuvir, another medicine for the treatment of $\mathrm{HCV}$, was affirmed. It has been affirmed for Food Drug Administration (FDA) on December 6, 2013. This medicine treats over $90 \%$ of patients and is fruitful against probably the most well-known $\mathrm{HCV}$ strains[1]. The concoction name is L-Alanine, N$\left[\left[\mathrm{P}(\mathrm{S}), 2^{\prime} \mathrm{R}\right]-2^{\prime}\right.$-deoxy-2'-fluoro-2'-methyl-P-phenyl-5'uridylyl]-, 1-methyl ethyl ester and C22H29FN3O9P [2] is its sub-atomic recipe. Sofosbuvir is a nucleotide simple and is a profoundly dynamic NS5B polymerase inhibitor in HCV. NS5B is one of the non-basic proteins basic for the blend of viral ribonucleic corrosive (RNA) [3]. In mix with numerous different medications with and without PEG-INF, Sofosbuvir has shown high adequacy against HCV [1].

Ribavirin is an antiviral medication which is nonparticular, antihepatitis. In 1970 it was combined. Its solid antiviral range action was accounted for in 1972 [4]. The compound name for this medication is $1-\beta-d-$ ribofuranosyl-1,2,4-triazole-3-carboxamide. Ribavirin is a remedially utilized simple of aguanosine as an expansive range antiviral agent [5].

Ribavirin had been explored for the treatment of HCV contamination in the mid 1990s. Notwithstanding perceptions of upgrades in serum aminotransferase levels [6] and hepatic histology [7], ribavirin had no huge impact on HCV RNA levels when utilized as a solitary operator. As respects virology freedom, drawing out the course of treatment didn't give any profit (Hoofnagle et al., 1996). Despite the fact that ribavirin was just utilized in blend for the therapy of interminable HCV infection [8].

Silymarin is a characteristic cancer prevention agent got from the seeds and products of the Silybum marianum plant(Milk thorn). It is made out of four flavonolignans, viz. Silybin, silydianin, isosilybin, and silychristin[9]. Milk thorn has been generally utilized for more than 2000 years in customary medication , particularly as a treatment for hepatic disorders [10]. It's known for its effect on hepatoprotection. This has been utilized to treat numerous liver sicknesses, including intense or constant viral hepatitis, hepatitis brought about by poisons, cirrhosis, and alcoholic hepatitis [11]. Silymarin capacities as a cell reinforcement, intracellular glutathione receptor, cell layer porousness stabilizer and receptor to keep hepatotoxic substances from coming to the hepatocytes. This additionally encourages the blend of ribosomal RNA reproducing liver recovery and forestalls the change of liver stellate cells into myofibroblasts, accordingly forestalling the affidavit of collagen strands in the liver[12,13].

\section{Materials and methods \\ 2.1 Animals}

Weight of 45 grown-up male pale skinned person mice (25-30) g was utilized. They were bought from the National Research Center in Dokki, Cairo(N.R.C.) and housed for seven days in plastic confines for convenience with our lab conditions.

\subsection{Tried medications}

As indicated by Paget and Barns condition, sofosbuvir was managed at a portion level of 50 $\mathrm{mg} / \mathrm{kg} /$ day[14]. This was broken down in the blink of an eye before ingestion of refined water. Portion sum for ribavirin was $20 \mathrm{mg} / \mathrm{kg} /$ day according to Rao \& Rahiman [15]. This was broken down in the blink of an eye before ingestion of refined water. Portion levels of Silymarin were infused at $70 \mathrm{mg} / \mathrm{kg} /$ day According to Mereish., et al [16]. This was broken up in Saline $75 / 25(\mathrm{v} / \mathrm{v})$ in propylene glycol. Every one of the prescriptions inspected were infused intraperitoneously. 


\subsection{Treatment schedule}

The trial creatures were arranged into 9 gatherings, each included 5 creatures. The creature got different medicines as appeared:

- Group (1): Control gathering, five mice not infused.

- Group (2): Solvent gathering, five mice were infused intraperitoneally with $0.5 \mathrm{ml}$ propylene glycol in saline75/25(v/v)daily for five days .

- Group (3): Ribavirin gathering, five mice were infused intraperitoneally with $0.5 \mathrm{ml}$ ribavirine every day for five days.

- Group (4): Sofosbuvir gathering, five mice were infused intraperitoneally with $0.5 \mathrm{ml}$ sofosbuvir every day for five days.

- Group (5): Ribavirin and Sofosbuvir gathering, five mice were infused intraperitoneally with $0.5 \mathrm{ml}$ ribavirine and sofosbuvir together every day for five days.

- Group (6): Silymarin gathering, five mice were infused intraperitoneally with $0.5 \mathrm{ml}$ silymarin every day for five days.

- Group (7): Ribavirin, Sofosbuvir and Silymarin gathering, five mice were infused intraperitoneally with $0.5 \mathrm{ml}$ ribavirine, sofosbuvir and silymarin every day for five days.

- Group (8): Ribavirin, Sofosbuvir then Silymarin gathering, five mice were infused intraperitoneally with $0.5 \mathrm{ml}$ ribavirine and sofosbuvir together every day for five days then with $0.5 \mathrm{ml}$ silymarin day by day for an additional five days.

- Group (9): Silymarin then Ribavirin , Sofosbuvir gathering, five mice were infused intraperitoneally with $0.5 \mathrm{ml}$ silymarin day by day for five days then with $0.5 \mathrm{ml}$ ribavirine and sofosbuvir together day by day for an additional five days.

\subsection{Cytogenetic evaluation}

\section{A) Chromosomal preparation experiment}

Out of the last injection animals were sacrificed after 24 hours. For mitotic index and chromosome aberration tests, the bone marrow cells were obtained from mice femurs. Savage reported [17].

\section{B) Sperm morphology assay}

Two epidedymis were taken from each mouse and carefully minced in isotonic solution with scissors to obtain sperms. Process the solution to remove large tissues. Sperm suspension was stained by 0.05 percent Eosin [18]. The suspension of sperm dispersed over a sterile slid and was examined under a light microscope. 1000 sperms for morphological abnormalities were examined for each specimen.

\subsection{Statistical analysis}

For each category the data were represented as mean+SE and subjected to ANOVA (one-way) statistical analysis. $\mathrm{P}<0.05$ was taken as value standard (Green, 2009).

\section{Results}

\subsection{Chromosomal evaluation}

The structural chromosomal aberration was observed in well-spread fields per mice of 50 metaphases. The standard sample in Fig (1a) shows that mice have 20 pairs of chromosomes. Chromosomal anomalies depicted as ring Fig (1b), deletion (figure 1c), chromatid fragmentation Figure (1d), centromeric attenuation Fig (1e), centralomeric fusion Fig (1f), end to end Fig (1 g).

\subsection{Total chromosomal aberration}

The data in table (1) and Fig (2) represent the mean value of total chromosome aberration in chromosome in 50 well spread bone marrow cells of the metaphase mice. The mean value of SL treated animals $(85.40 \pm 5.59)$ was substantially higher than the control group (12.60 \pm 2.62$)$. However this is due to the high

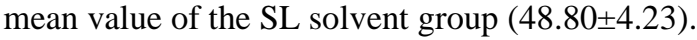

The mean value of $S$ and $R$ treated animals $(217.6 \pm 10.99)$ as opposed to the control group $(12.60 \pm 2.62)$ was very significantly increased. When $\mathrm{SL}$ is injected before $\mathrm{S}$ and $\mathrm{R}$ drugs to protect cells, it decreases the mean value $(180.00 \pm 3.89)$ as compared to $\mathrm{S}$ and $\mathrm{R}$ alone $(217.6 \pm 10.99)$.

If $\mathrm{SL}$ is combined with drugs $\mathrm{S}$ and $\mathrm{R}$, the mean value falls to $(183.20 \pm 4.91)$ as opposed to $S$ and $R$ alone (217.6 \pm 10.99$)$. But the highly significant decrease in the mean value is obtained when SL was used as a treatment, after $\mathrm{S}$ and $\mathrm{R}$ the mean value decreased to $(117.4 \pm 4.58)$ compared to $\mathrm{S}$ and $\mathrm{R}$ alone (217.6 \pm 10.99$)$.

Both of these findings suggest that using SL as a treatment after treatment with $\mathrm{S}$ and $\mathrm{R}$ was more effective than the preventive effect of SL and at the same time as administering both SL and S and R in minimizing the overall chromosomal abberation caused by treatment with $\mathrm{S}$ and $\mathrm{R}$.

\subsection{Sperm morphology evaluation}

Table (2) and Fig (3) data represent the mean value of total abnormlity of the sperm. These data indicate that the mean value between the control group $(14.00 \pm 2.69)$ and the SL group $(70.65 \pm 13.41)$ had substantially improved.

The mean values of $\mathrm{S}$ and $\mathrm{R}$ treated animals $(110.00 \pm 21.15)$ as opposed to the control group $(14.00 \pm 2.69)$ were very increased significantly. When $\mathrm{SL}$ is injected before $\mathrm{S}$ and $\mathrm{R}$ drugs to protect the cell, it reduces the mean value $(56.67 \pm 10.04)$ as opposed to $\mathrm{S}$ and $\mathrm{R}$ alone (110.00 \pm 21.15$)$.

If $\mathrm{SL}$ is combined with drugs $\mathrm{S}$ and $\mathrm{R}$, the mean value falls to $(34.66 \pm 7.15)$ as opposed to $S$ and $R$ alone $(110.00 \pm 21.15)$. But the highly significant decrease in the mean value is obtained when SL was used as a treatment, after $\mathrm{S}$ and $\mathrm{R}$ the mean value decreased to (22.33 \pm 7.33$)$ compared to $\mathrm{S}$ and $\mathrm{R}$ alone

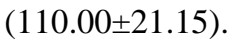

The findings also show that using SL as a treatment after treatment with $\mathrm{S}$ and $\mathrm{R}$ was more effective than its protective effect and at the same time decreasing the 
total sperm abnormalities than injecting both SL and S and $\mathrm{R}$.
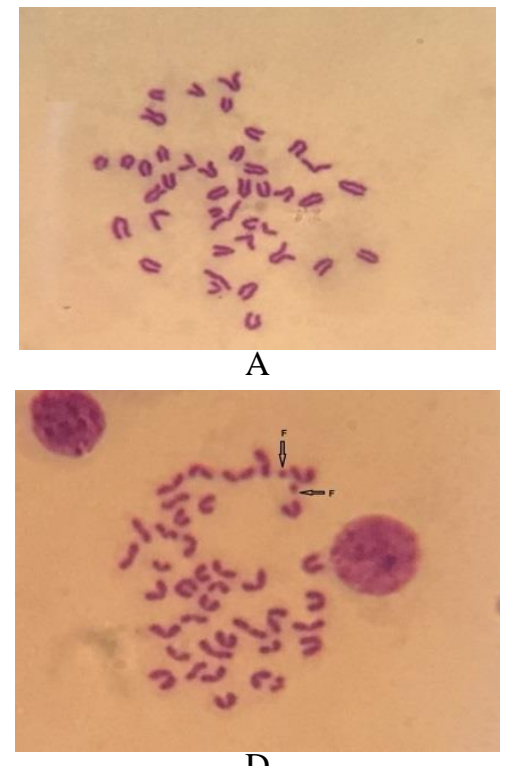

D

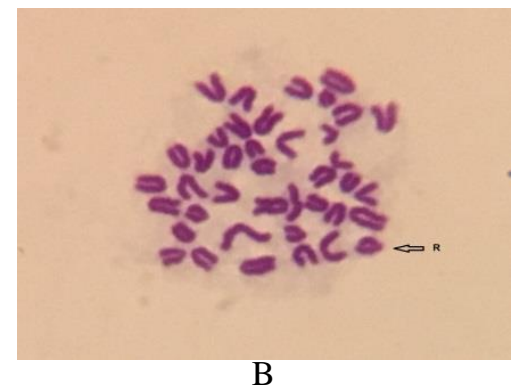

B

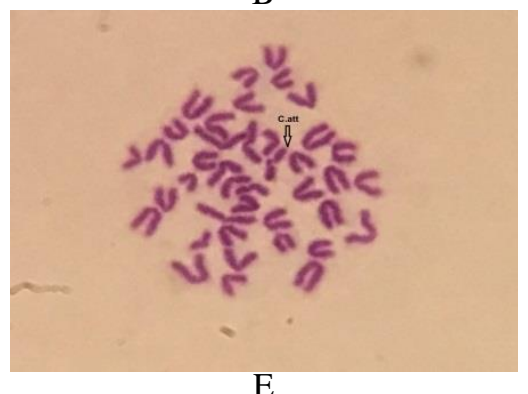

$\mathrm{E}$

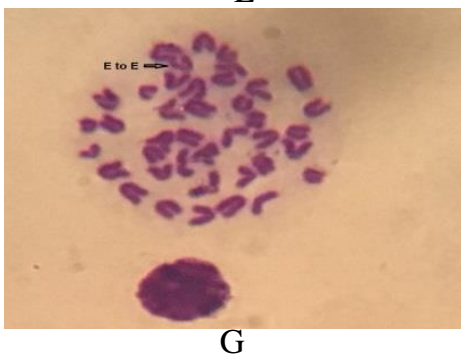

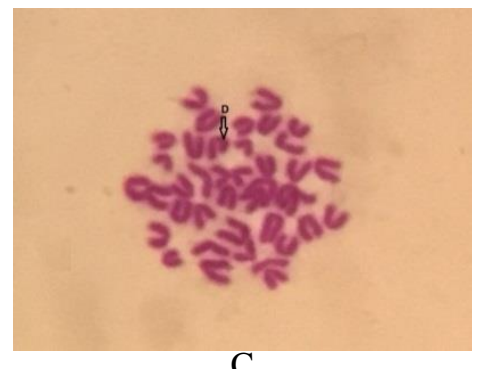

C

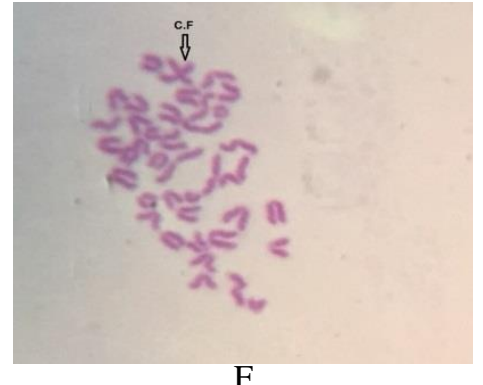

F

Fig (1) A) Normal chromosome. B) Ring. C) Deletion. D) Chromatid fragmentation. E) Centromeric attenuation. F) Centromericfussion. G) End to End.

Table (1) The average structural chromosomal aberration in mice bone marrow cells.

\begin{tabular}{lccccccc}
\hline \multicolumn{7}{c}{ No. of structural and numerical aberration } & \\
\hline Groups & Ring & Deletion & $\begin{array}{c}\text { chromatid } \\
\text { fragmantation }\end{array}$ & $\begin{array}{c}\text { Centromeric } \\
\text { attenuation }\end{array}$ & centromericfussion & end to end & $\begin{array}{c}\text { Total } \\
\text { aberrations }\end{array}$ \\
\hline control & $(4.40 \pm 0.68)$ & $(2.60 \pm 0.51)$ & $(2.00 \pm 0.32)$ & $(1.00 \pm 0.55)$ & $(1.00 \pm 0.32)$ & $(1.60 \pm 0.24)$ & $(12.60 \pm 2.62)$ \\
Solvent & $(9.80 \pm 0.66)$ & $(15.00 \pm 0.84)$ & $(5.40 \pm 0.68)$ & $(8.20 \pm 0.58)$ & $(5.60 \pm 0.81)$ & $(4.80 \pm 0.66)$ & $(48.80 \pm 4.23)$ \\
R & $(22.00 \pm 1.14)$ & $(26.80 \pm 1.36)$ & $(14.00 \pm 1.14)$ & $(34.00 \pm 2.66)$ & $(14.40 \pm 2.34)$ & $(10.20 \pm 1.11)$ & $(121.40 \pm 9.75)$ \\
S & $(19.40 \pm 1.94)$ & $(34.80 \pm 2.13)$ & $(17.40 \pm 2.20)$ & $(44.20 \pm 3.68)$ & $(12.00 \pm 0.71)$ & $(15.00 \pm 1.55)$ & $(209.80 \pm 12.21)$ \\
R+S & $(27.20 \pm 1.77)$ & $(39.40 \pm 2.18)$ & $(23.80 \pm 1.16)$ & $(86.80 \pm 3.88)$ & $(20.60 \pm 1.08)$ & $(19.80 \pm 0.92)$ & $(217.60 \pm 10.99)$ \\
SL & $(10.60 \pm 0.67)$ & $(15.60 \pm 1.60)$ & $(15.80 \pm 1.02)$ & $(27.00 \pm 1.58)$ & $(9.20 \pm 0.32)$ & $(7.20 \pm 0.37)$ & $(85.40 \pm \pm .59)$ \\
R+S+SL & $(18.60 \pm 0.51)$ & $(35.20 \pm 0.66)$ & $(21.40 \pm 0.51)$ & $(72.20 \pm 1.36)$ & $(19.40 \pm 1.36)$ & $(16.40 \pm 0.51)$ & $(183.20 \pm 4.91)$ \\
SL- & $(21.40 \pm 0.51)$ & $(32.60 \pm 0.68)$ & $(20.40 \pm 0.75)$ & $(70.80 \pm 0.80)$ & $(18.00 \pm 0.45)$ & $(16.80 \pm 0.80)$ & $(180.00 \pm 3.89)$ \\
S+R & & & & & & & \\
S+R-- & $(13.20 \pm 0.80)$ & $(19.40 \pm 0.87)$ & $(23.80 \pm 0.58)$ & $(40.40 \pm 1.24)$ & $(10.20 \pm 0.58)$ & $(10.40 \pm 0.51)$ & $(117.4 \pm 4.58)$ \\
SL & & & & & & & \\
\hline
\end{tabular}

$\mathrm{R}=$ Ribavirin

$\mathrm{S}=$ Sofosbuvir

** Highly Significant $(\mathrm{P} \leq 0.01)$
$\mathrm{SL}=$ Silymarin . *** Very Highly Significant $(\mathrm{P} \leq 0.001$

* Significant $(\mathrm{P} \leq 0.05)$ 


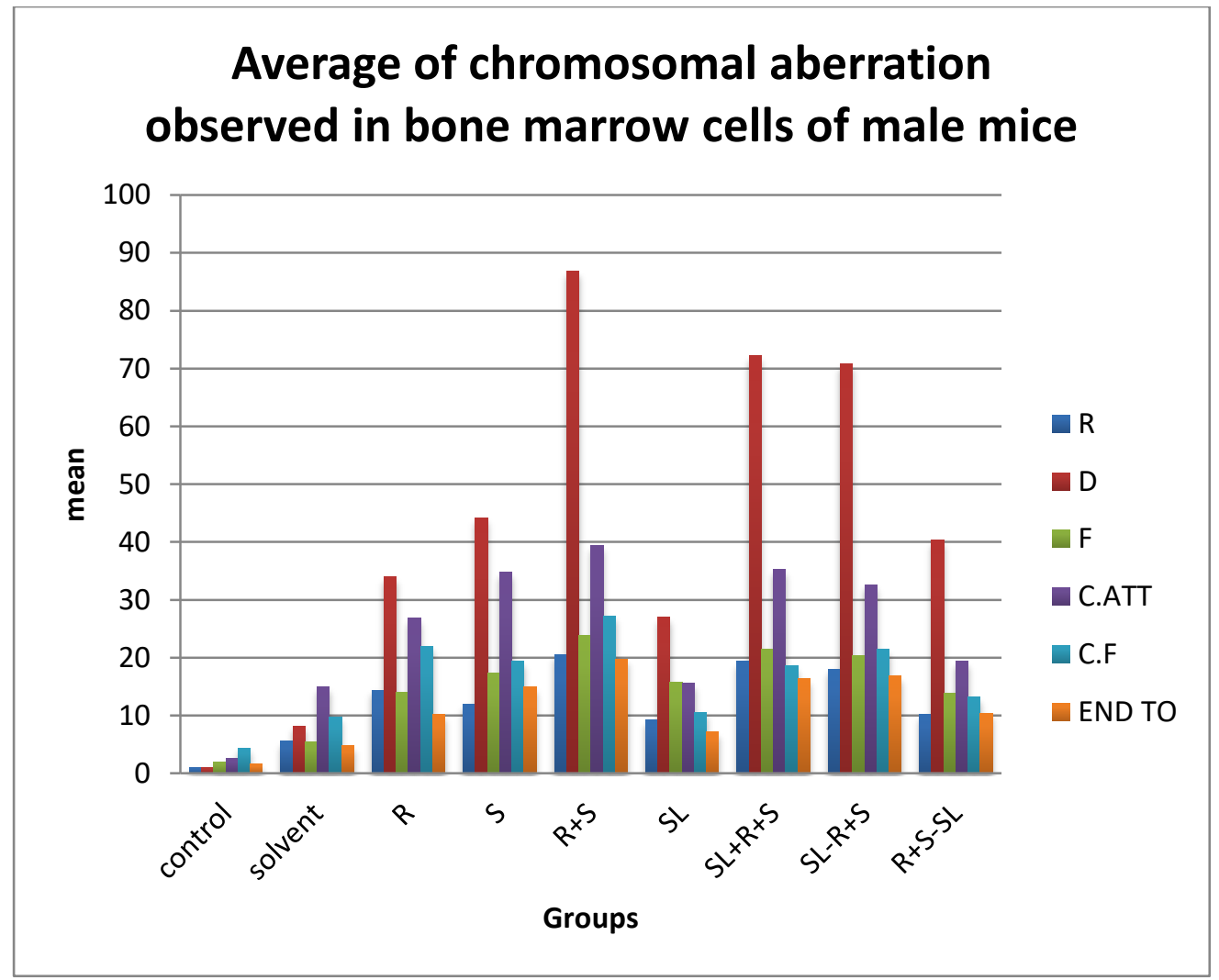

Fig (2) The average structural chromosomal aberrationin mice bone marrow cells. $\mathrm{R}=$ Ribavirin . $\quad \mathrm{S}=$ Sofosbuvir . $\quad \mathrm{SL}=$ Silymarin .

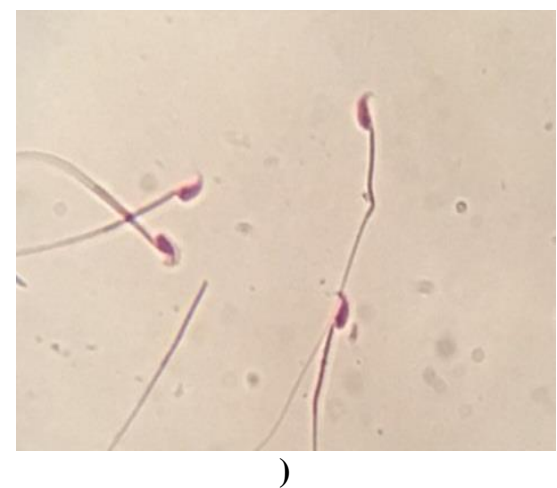

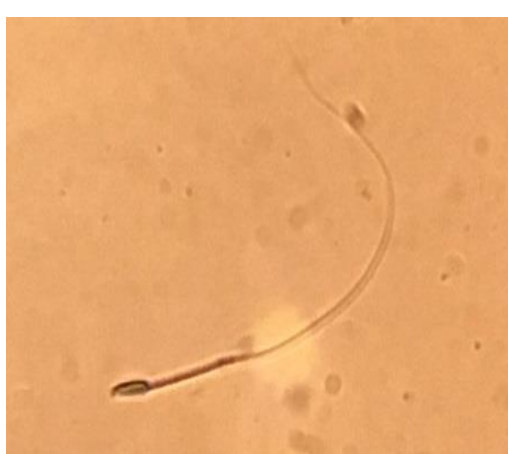

B)

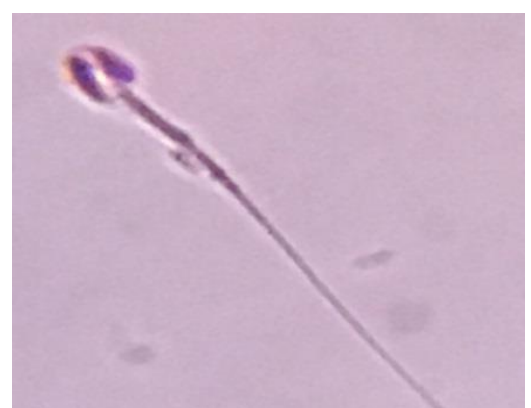

D)

Fig (3) A) Normal sperm. B) Without hook. C) Banana. D) Amorphous. E) Hummer. 
Table (2) The average of the sperm head abnormalities in male mice.

\begin{tabular}{|c|c|c|c|c|c|c|c|c|c|c|c|c|c|c|c|}
\hline \multirow{3}{*}{$\begin{array}{l}\text { Groups } \\
\text { control }\end{array}$} & \multicolumn{12}{|c|}{$\begin{array}{r}\text { No. of structural and numerical aberration } \\
\end{array}$} & \multirow{2}{*}{\multicolumn{3}{|c|}{$\begin{array}{c}\text { Total } \\
\text { aberrations }\end{array}$}} \\
\hline & \multicolumn{3}{|c|}{ Without hook } & \multicolumn{3}{|c|}{ Banana } & \multicolumn{3}{|c|}{ Amorphous } & \multicolumn{3}{|c|}{ Hummer } & & & \\
\hline & 7.00 & \pm & 0.58 & 5.33 & \pm & 1.20 & 0.67 & \pm & 0.33 & 1.00 & \pm & 0.58 & 14.00 & \pm & 2.69 \\
\hline Solvent & 8.33 & \pm & 0.88 & 8.33 & \pm & 1.86 & 2.00 & \pm & 0.58 & 1.33 & \pm & 0.33 & 19.99 & \pm & 3.65 \\
\hline $\mathbf{R}$ & 34.67 & \pm & 4.10 & 33.33 & \pm & 9.26 & 4.00 & \pm & 1.73 & 2.00 & \pm & 0.00 & 74.00 & \pm & 15.09 \\
\hline $\mathbf{S}$ & 37.33 & \pm & 1.45 & 83.00 & \pm & 4.73 & 5.66 & \pm & 0.88 & 3.00 & \pm & 1.15 & 128.99 & \pm & 8.21 \\
\hline $\mathbf{R}+\mathbf{S}$ & 24.67 & \pm & 6.64 & 67.67 & \pm & 12.03 & 9.00 & \pm & 1.15 & 8.66 & \pm & 1.33 & 110 & \pm & 21.15 \\
\hline SL & 20.33 & \pm & 2.91 & 43.00 & \pm & 9.29 & 3.66 & \pm & 0.33 & 3.66 & \pm & 0.88 & 70.65 & \pm & 13.41 \\
\hline $\mathbf{R}+\mathbf{S}+\mathbf{S L}$ & 15.00 & \pm & 3.79 & 16.33 & \pm & 1.33 & 2.00 & \pm & 1.15 & 1.33 & \pm & 0.88 & 34.66 & & 7.15 \\
\hline $\mathbf{S L}-\mathbf{S}+\mathbf{R}$ & 31.00 & \pm & 5.51 & 17.33 & \pm & 2.03 & 4.67 & \pm & 1.67 & 3.67 & \pm & 0.83 & 56.67 & \pm & 10.04 \\
\hline S+R--SL & 11.00 & \pm & 5.00 & 6.00 & \pm & 1.00 & 2.33 & \pm & 0.33 & 3.00 & \pm & 1.00 & 22.33 & \pm & 7.33 \\
\hline
\end{tabular}

$$
\mathrm{R}=\text { Ribavirin } . \quad \mathrm{S}=\text { Sofosbuvir } . \quad \mathrm{SL}=\text { Silymarin . }
$$

*** Very Highly Significant $(\mathrm{P} \leq 0.001)$

* Significant $(\mathrm{P} \leq 0.05) \quad * *$ Highly Significant $(\mathrm{P} \leq 0.01)$

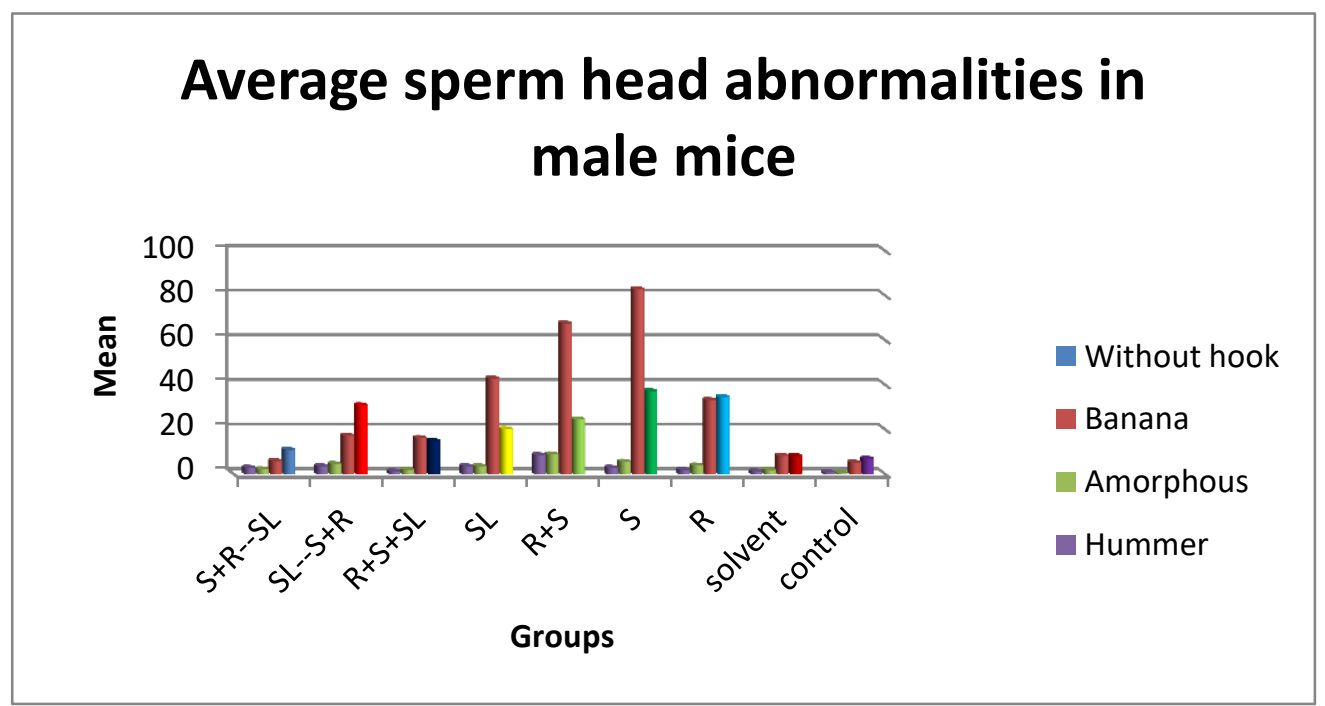

$$
\mathrm{R}=\text { Ribavirin . } \quad \mathrm{S}=\text { Sofosbuvir . }
$$

\section{Discussion}

The objective of this investigation is to decide the defensive impact of silymarin on the chromosome and sperm as a characteristic item against the reactions of sofosbuvir and ribavirin as an antiviral medication. There have been not many distributed examinations on the effect of sofosbuvir and sofosbuvir - ribavirin on chromosomes and sperms in creatures when utilizing these drugs, as far as anyone is concerned. Our examination discoveries have demonstrated that ribavirin and sofosbuvir as an antivirous drug cause cytogenetic impacts, including chromosome ring, cancellation, chromatid discontinuity, centromeric weakening, and end-to - end combination. These malities observed in male mice.

$\mathrm{SL}=$ Silymarin Discussion

discoveries coordinated (Narayana .et $a l$,) who announced genotoxic and cytotoxic rodent bone marrow ribavirin[19]. Additionally, (Seetharama,) said ribavirin is a powerful mutagen that causes chromosome basic harm, and goes about as a cytotoxic specialist in mice. This present medication's genotoxicity isn't polished under portion subordinate pattern [20]. There have likewise been a few human preliminaries that concur with these resutls as, (Tatar et al) revealed that ribavirin has a genotoxic impact reversible in vivo in humans [21]. It distributed comparative outcomes (Tatar,). These discoveries uncovered that ribavirin has a reversible genotoxic 
impact in people and this impact might be ascribed to ribavirin harmful metabolites [22].

The discoveries additionally recommend that sofosbuvir and ribavirin cause mice sperm head imperfections, for example, without pin, banana, nebulous, and head structure hammer. These discoveries concur with (Narayana, et al ) who revealed that ribavirin essentially influences the morphology of the sperm and is a mutagen of the germ cells in rodents [23]. Also,(Narayana, et al ) announced that ribavirin or its metabolites go about as cytotoxins in rodent testis and have a portion and time-subordinate impact on the epidididymal sperm count [24].

Additionally, (D'Souza,) and (Seetharama \& Narayana) who said ribavirin initiates point transformations in the germ cells consequently actuating unpredictable sperm formation[25,20]. Comparative discoveries were distributed ribavirin was related with harmfulness of reversible germ cells, mutagenicity, and diminishes in the sperm count [26]. In addition,(El-Kholy, et al) announced that sovaldi and sovaldi-ribavirin actuated regenerative issues as uncovered by diminished serum testosterone levels, poisonous and degenerative consequences for test histology [27].

In our investigation, we found that almost all gatherings that infused silymarin either previously or after or with the medication influence chromosomal abbarism and sperm anomalies to diminish. These discoveries are steady with who led genotoxicity tests on silymarin to demonstrate the function of cell harm chromosomes and conceptive cells in warm blooded animals little mouse bone marrow micronucleus test and sperm variation from the norm test with the first core cells and eukaryotic cells, regenerative cells and physical, in vivo and in vitro cells. Silymarin was recognized negative in both of these test results [28]. Additionally, who inferred that RBV in mice is a genotoxic and cytotoxic medication, and that silymarin pretreatment limits this harmfulness. Use of silymarin as a preventive prescription is prompted in patients taking RBV as a restorative antiviral drug[29].

\section{Conclusion}

As seen in the tests, sofosbuvir and ribavirin cause chromosome aberration to the structure. Circle, deletion, fragmentation of chromatids, centromeric attenuation, centralomeric fusion, and end to end were observed. They also cause head anomalies to include sperm without hook, banana, amorphous head and hummer head. Using silymarin as a medication to combat the side effect of sofosbuvir and ribavirin is so successful.

\section{References}

[1] E.GOLANTY, G. EDLIN. Health, Wellness, 12th edit. Jones ,Bartlett Publishers, Vol.USA, PP.272, 2015.

[2] H. BHATIA, H. SINGH, N. GREWAL N. NATT. So-fosbuvir: A novel treatment option for chronic hepatitis C infection. J Pharmacol Pharmacother, Vol.5(4), pp. 278-284, 2014.

[3] AM. LAM, C. ESPIRITU, S. BANSAL, MICOLOCHICK STEUER HM, NIU C, ZENNOU $\mathrm{V}$ Genotype and subtype pro-ling of PSI-7977 as a nucleotide inhi-bitor of hepatitis $\mathrm{C}$ virus. Antimicrob Agents Chemot-her, Vol.56, pp 33593368, 2012.

[4] RW. SIDWELL, JH. HUFFMAN, GP. KHARE Broad-spectrum antiviral activity of Virazole: 1beta-D-ribofuranosyl-1, 2, 4-triazole-3carboxamide. Science, Vol.177,PP. 705-706, (1972).

[5] R.W. Sidwell, J.H. Huffman, G.P. Khare, L.B. Allen, J.T. Witkowski, R.K. Robins. Broadspectrum antiviral activity of virazole: 1-_-dribofuranosyl-1,2,4-triazole-3-carboxamide, Science 177 705-706.

[6] DI BISCEGLIE AM, CONJEEVARAM HS, FRIED MW (1995) Ribavirin as therapy for chronic hepatitis C. A randomized, double-blind, placebocontrolled trial. Ann Intern Med, Vol.123, PP. 897903, 1972.

[7] JH. HOOFNAGLE. LAU D, CONJEEVARAM H Prolonged therapy of chronic hepatitis C with ribavirin. J Viral Hepat, Vol.3, PP. 247-252, 1996.

[8] H. TE, G. RANDALL.JENSEN D Mechanism of action of ribavirin in the treatment of chronic hepatitis C. GastroenterolHepatol, Vol.3(3), PP. 218-225, 2007.

[9] K. Wellington, B. Jarvis. Silymarin: a review of its clinical properties in the management of hepatic disorders, BioDrugs, Vol.15 (7), PP. 465-489, 2001.

[10] A. Svobodov, A. Zda_rilov, J. Mali_skov, H. Mikulkov, D. Walterov. Attenuation of UVAinduced damageto human keratinocytes by silymarin. J DermatolSci, Vol.46, PP.21-30, 2007.

[11] V. Kashaw, AK. Nema, A. Agarwal. Hepatoprotective prospective of herbal drugs and their vesicular carriers-A review. International J.,Research in Pharmaceutical and Biomedical Sciences, Vol.2, PP. 360-374, 2011.

[12] V. Kashaw, AK. Nema, A. Agarwal. Hepatoprotective prospective of herbal drugs and their vesicular carriers-A review. International J.,Research in Pharmaceutical and Biomedical Sciences, Vol.2, PP.360-374, 2011.

[13] FA. Crocenzi, MG. Roma, Silymarin as a newhepatoprotective agent in experimental cholestasis: new possibilities for an ancient medication. Curr Med Chem ,Vol.13, PP.10551074, 2006.

[14] G.E. Paget, G.M. Barnes. Evaluation of Drug Activities, Vol. 1. Academic Press, London, 1964.

[15] K.S.Rao, M.A. Rahiman.Cytogenetic effects of ribavirin on mouse bone marrow. Mutation Research/Genetic Toxicology, Vol.224(2), pp.213218, 1989. 
[16] K.A. Mereish, D.L. Bunner, D.R. Regland, D.A. Creasia. Protection against microcystin-L.R. induced hepatotoxicity by silymarin: biochemistry, histopathology and lethality, Pharmacol. Res, Vol.8,pp. 257-277, 1991.

[17] J.R. Savage. Classification and relationships of induced chromosomal structual changes. J.,medical genetics, Vol.13(2), pp.103-122, 1976.

[18] A. Mukherjee, A. K. Giri, A.Sharma, G.Talukder. Relative Efficiency of short-term tests in detecting genotoxic effects of cadmium Chloride in mice in vivo. J. Mutation Research, Vol.206 (2),PP. 285295, 1988.

[19] K.Narayana, U.J. D’Souza, K.S. Rao. The genotoxic and cytotoxic effects of ribavirin in rat bone marrow. Mutation Research/Genetic Toxicology and Environmental Mutagenesis, Vol.521(1-2), PP.179-185, 2002.

[20] K. P. SeetharamaRao, K. Narayana. In vivo chromosome damaging effects of an inosine monophosphate dehydrogenase inhibitor: Ribavirin in mice. Indian J Pharmacol,Vol, 37, PP.90-5,2005.

[21] A.Tatar, Z.Ozkurt, I.Kiki. Genotoxic effect of ribavirin in patients with Crimean-Congo hemorrhagic fever. Japanese J.,infectious diseases, Vol.58(5), PP.313, 2005.

[22]A.Tatar,Z.Özkurt,A.HACIMÜFTÜOĞLU,A.YEŞİ LYURT, S.Vancelik. Evaluation of ribavirin genotoxicity with sister chromatid exchange and micronuclei assays in humans. Turkish J.,Medical Sciences, Vol.39(2), PP.241-246, 2009.

[23] K.Narayana, U.J. D Souza, K.S. Rao.Effect of ribavirin on epididymal sperm count in rat. Indian
J.,physiology and pharmacology, Vol.46(1), PP.97101, 2002.

[24] K. Narayana, U.J. D'Souza, K.S. Rao.Ribavirininduced sperm shape abnormalities in Wistar rat. Mutation Research/Genetic Toxicology and Environmental Mutagenesis, Vol.513(1-2), pp.193196, 2002.

[25] U.J. D'Souza, K. Narayana. Mechanism of cytotoxicity of ribavirin in the rat bone marrow and testis. Indian J., physiology and pharmacology, Vol.46(4), PP.468-474, 2002.

[26] K.S. Rao, K.Narayana. In vivo chromosome damaging effects of an inosine monophosphate dehydrogenase inhibitor: Ribavirin in mice. Indian J.,pharmacology, Vol.37(2), PP.90, 2005.

[27] W.B. El-KholyFaried, M.A. Salama, R.M. ElFiky, I. El-Garawani. Evaluation of testicular cytotoxicity and genotoxicity of sofosbuvir and sofosbuvir-ribavirin in the adult male albino rats. European J.,anatomy, Vol.23(6), PP.393-403, 2019.

[28] F.Zhao, X.H. Li. Preliminary toxicology evaluation of silymarin. In Advanced Materials Research Trans Tech Publications Ltd, Vol.1049, PP. 544-546, 2014.

[29] M. M. Noshy, N. A.Hussien, A. A. ElGhor.Evaluation of the role of the antioxidant silymarin in modulating the in vivo genotoxicity of the antiviral drug ribavirin in mice. Mutation Research/Genetic Toxicology and Environmental Mutagenesis, Vol.752(1-2), PP.1420. doi:10.1016/j.mrgentox,2012. 